\title{
Evidence from ileum and liver transcriptomes of resistance to high-salt and water-deprivation conditions in camel
}

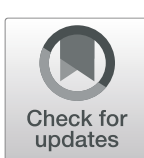

Dong Zhang ${ }^{1 \dagger}$, Jing Pan ${ }^{1 \dagger}$, Huanmin Zhou ${ }^{1 *}$ and Yu Cao ${ }^{1,2^{*}}$

\begin{abstract}
Camels have evolved various resistance characteristics adaptive to their desert habitats. In the present study, we used high-throughput sequencing to investigate stress-induced alternative splicing events as well as different genes involved in resistance to water deprivation and salt absorption in the ileum and liver in Camelus bactrianus. Through association analyses of mRNA, miRNA and IncRNA, we sought to explicate how camels respond to high salt and water scarcity conditions. There were two modes by which genes driven by alternative splicing were enriched to molecular functions, invoking of which was potentially fixed by organ and stress types. With qRT-PCR detection, the differentially expressed MUC6, AQP5, LOC105076960, PKP4, CDH11, TENM1, SDS, LOC105061856, PLIN2 and UPP2 were screened as functionally important genes, along with miR-29b, miR-484, miR-362-5p, miR-96, miR-195, miR-128 and miR-148a. These genes contributed to cellular stress resistance, for instance by reducing water loss, inhibiting excessive import of sodium, improving protective barriers and sodium ion homeostasis, and maintaining uridine content. The underlying competing endogenous RNAs referred to LNC001664, let-7e and LOC105076960 mRNA in ileum, and LNC001438, LNC003417, LNC001770, miR-199c and TENM1 mRNA in liver. Besides competent interpretation to resistance, there may be inspirations for curing human diseases triggered by high-salt intake.
\end{abstract}

Keywords: Camelus bactrianus, lleum, Liver, Salt stress, Water-deprivation stress

\section{Background}

Over the course of evolution, desert camels have developed many adaptive characteristics supporting resistance to heat, salt, and dry environments $[1,2]$. Prior studies have reported that camels respond to high-salt and water shortage conditions by increased sodium excretion under saline loading [3], production of highly concentrated urine [4], and efficient water reservation by the kidneys [5]. Notably, previous studies on camels have focused on the role of the kidney in resistance to water deprivation, but neglected other organs, such as liver and intestine. Investigations in humans and

\footnotetext{
*Correspondence: zhouhuanminim@163.com; yucaoitcm@tjutcm.edu.cn ${ }^{\dagger}$ Dong Zhang and Jing Pan contributed equally to this work.

${ }^{1}$ College of Life Sciences, Inner Mongolia Agricultural University, No. 306 Zhaowuda Road, Hohhot 010018, P.R. China

Full list of author information is available at the end of the article
}

other model species have shown that the intestinal tract is widely coupled to the regulation of salt and water metabolism [6]. The ileum is the third and final portion of the small intestine, primary function of which is to absorb minerals and nutrients from ingested food $[7,8]$. The ileum forms a peritoneal structure with blood vessels, lymphatic vessels, and nerve fibers, suspended within the mesentery. The blood vessels, including the superior mesenteric artery and veins supply the ileum [9]. In rat, sodium is absorbed and transported from mucosa to serosa by the ileum, while water absorption is passive and dependent on osmotic gradients, such as those forced by active salt transport $[6,10,11]$. Additionally, sodium ion absorption is modulated by hormones (e.g. vasopressin and renin) in body fluids and by proteins (e.g. EnAC complex and $\mathrm{Na}^{+} / \mathrm{K}^{+}$ATP enzymes) in intestinal epithelial cells [12]. In hepatic cells, bile salt export pump

(C) The Author(s). 2020 Open Access This article is licensed under a Creative Commons Attribution 4.0 International License, which permits use, sharing, adaptation, distribution and reproduction in any medium or format, as long as you give appropriate credit to the original author(s) and the source, provide a link to the Creative Commons licence, and indicate if changes were made. The images or other third party material in this article are included in the article's Creative Commons licence, unless indicated otherwise in a credit line to the material. If material is not included in the article's Creative Commons licence and your intended use is not permitted by statutory regulation or exceeds the permitted use, you will need to obtain permission directly from the copyright holder. To view a copy of this licence, visit http://creativecommons.org/licenses/by/4.0/ The Creative Commons Public Domain Dedication waiver (http://creativecommons.org/publicdomain/zero/1.0/) applies to the data made available in this article, unless otherwise stated in a credit line to the data. 
and sodium taurocholate cotransporting polypeptide have been identified as salt-related transport proteins [13]. Previous reports have detected higher metal levels in the salt glands of mallard (Anas platyrhynchos) and black duck (Anas rubripes), as well as in the liver of greater scaup (Aythya marila) [14]. However, data on the post-transcriptional regulation of non-coding RNA in the ileum and liver under salt and water-deprivation stresses remain scarce.

Non-coding RNAs (ncRNAs), such as long non-coding RNA (lncRNA) and micro RNA (miRNA), are generally interpreted as RNA molecules that are not translated into proteins [15]. Post-transcriptional regulation mediated by ncRNA is an essential factor on affecting gene expression. Studies have demonstrated that miRNA can inhibit the expression of protein-coding genes by binding to $3^{\prime}$ untranslated regions and protein-coding regions of a targeted mRNA [16, 17]. The competing endogenous RNA (ceRNA) theory posits that lncRNA acts as a molecular sponge for miRNAs and reverses the inhibition protein-coding expression they evoke [18]. In the present study, we exploited these two patterns of miRNA-mRNA and ceRNA to explore regulatory responses to external stresses of salt and water-deprivation in camel.

In addition to illustrating molecular responses in camel organs under stress, we hope to provide novel insights based on scientific evidence to support the development of new treatment strategies for human diseases caused by high-salt diets.

\section{Materials and methods}

\section{Stress application and sample collection}

Nine Alxa bactrian camels were randomly allocated into two experimental groups (salt stress and waterdeprivation stress) and one control group (free diet), with three camels per group and a treatment phase of 24 days. The mean \pm SD weight of all camels was $350.48 \pm 7.68 \mathrm{~kg}$, and the average age was $7.67 \pm 0.71$ years old. Salt stress (SS) group was treated as follows: salt intake base was $200 \mathrm{~g} / \mathrm{d}$, and increased by $100 \mathrm{~g}$ every three days $[19,20]$. Water-deprivation stress (WS) group was with free feed intake but fasting water. Mercy-killing was performed to nine Alxa bactrian camels by severing the carotid artery after intramuscular injection of $0.5 \mathrm{mg} / \mathrm{kg}$ xylazine [21]. Ileum and liver tissues were immediately sampled and stored in $1.5 \mathrm{~mL}$ frozen tubes with liquid nitrogen $\left(-196^{\circ} \mathrm{C}\right)$, respectively.

\section{RNA isolation and quantification}

RNeasy Mini Kit (QIAGEN, Germany) was used to extract the total RNA from ileum and liver tissues of the nine camels. RNA purity, concentration and integrity were detected using the NanoPhotometer spectrophotometer (IMPLEN, CA, USA), Qubit RNA Assay Kit in Qubit 2.0 Fluorometer (Life Technologies, CA, USA) and RNA Nano 6000 Assay Kit with the Agilent Bioanalyzer 2100 system (Agilent Technologies, CA, USA) consecutively.

\section{Library preparation, clustering and sequencing for IncRNA and small RNA}

The amount of $3 \mu \mathrm{g}$ total RNA per sample was inputted separately to construct libraries of lncRNA and small RNA. For lncRNA library construction, ribosomal RNA was first removed by Epicentre Ribo-zero rRNA Removal Kit (Epicentre, USA), after which libraries were prepared by using NEBNext Ultra Directional RNA Library Prep Kit for Illumina (NEB, USA). NEBNext Multiplex Small RNA Library Prep Set for Illumina (NEB, USA) was used to prepare the small RNA libraries. Clustering of the index-coded samples was executed on a cBot Cluster Generation System using TruSeq PE Cluster Kit v3-cBot-HS (Illumina) for lncRNA, and TruSeq SR Cluster Kit v3-cBot-HS (Illumina) for small RNA. The library constructions of lncRNA and small RNA were performed respectively on an Illumina HiSeq 4000 platform and Illumina HiSeq 2500 platform via pooled RNA-seq [22].

\section{Analysis of miRNA and IncRNA data}

Regarding data processing, quality control, reads mapping to Camelus bactrianus genome via TopHat v2.0.9 (parameters: --library-type fr-firststrand) [23], transcript assembly via Cufflinks (parameters: min-frags-per-transfrag $=0)$ [24], IncRNA and mRNA sorting via CNCI v2 were performed at default parameters [25], CPC 0.9-r2 (parameters: -evalue 1e-10) [26], Pfam Scan v1.3 (parameters: -E 0.001 --domE 0.001 -pfamB) [27, 28], PhyloCSF v20121028 (parameters: --orf = ATGStop; - frames = 3; -removeRefGaps) [29], mRNA and lncRNA annotation via Camelus bactrianus and Bos Taurus databases, differential expression analysis via Cuffdiff (http://coletrapnell-lab.github.io/cufflinks/cuffdiff/index.html), target gene prediction via lncRNA gene upstream/downstream $100 \mathrm{~kb}$ and Pearson Correlation Coefficient with |Pearson correlation $\mid>0.95$ [30], Gene Ontology (GO) and Kyoto Encyclopedia of Genes and Genomes (KEGG) pathway enrichment analyses of protein-coding genes of differential expression via Enrichr [31, 32], DAVID 6.8 [33, 34] and KOBAS 2.0 (parameters: blastx 1e-10 and padjust: $\mathrm{BH}$ ) [35] were implemented for lncRNA data analysis. Quality control, reads mapping to Camelus bactrianus genome via Bowtie (parameters: -v 0 - $\mathrm{k} 1$ ) [36], novel miRNA prediction via miREvo (parameters: $-\mathrm{i}$ -r -M -m -k -p 10 -g 50,000) [37] and mirdeep2 (parameters: quantifier.pl -p -m -r -y -g 0 -T 10) [38], differential expression analysis via TPM [39] and DEGseq with qvalue $<0.01$ and $\mid \log 2$ (foldchange) $\mid>1$ [40], small RNA annotation by Bos taurus database, target gene prediction via miRanda (parameters: -sc 140 -en - 10 -scale 4 -strict -out) were ran for data analysis of small RNA. 


\section{Quantitative detection}

RNA was isolated from ileum and liver tissues of camel via mirVana miRNA Isolation Kit (Ambion, USA). The primers were designed by Primer Express 3.0.1 (Additional file 1: Table S1) and qRT-PCR was performed using $7900 \mathrm{HT}$ Sequence Detection System (ABI, USA), following the manufacturer's protocol, with ReverTra Ace qPCR RT Kit (TOYOBO, Japan) and Power SYBR Green PCR Master Mix (ABI, USA). The student's t test was performed to compare the mean values between groups and a $P$-value of less than 0.05 was considered as statistically significant.

\section{Results}

Differential alternative splicing events under salt and water-deprivation stresses

In the ileum and liver of salt stress (SS) and waterdeprivation stress (WS) groups, five alternatively splicing (AS) categories were statistically analysed, including skipped exon (SE), retained intron (RI), mutually exclusive exons (MXE), alternative $5^{\prime}$ splice site (A5SS) and alternative 3' splice site (A3SS) (Fig. 1a). Focusing on event number of differential alternative splicing $(P<0.05)$, there were 239 (ileum under salt stress, SSI), 579 (ileum under water-deprivation stress, WSI), 174 (liver under salt stress, SSL) and 233 (liver under water-deprivation stress, WSL) in skipped exon, 7 (SSI), 17 (WSI), 7 (SSL) and 3 (WSL) in retained intron, 87 (SSI), 139 (WSI), 97 (SSL) and 156 (WSL) in mutually exclusive exons, 17 (SSI), 40 (WSI), 19 (SSL) and 18 (WSL) in alternative $5^{\prime}$ splice site, 33 (SSI), 70 (WSI), 26 (SSL) and 24 (WSL) in alternative $3^{\prime}$ splice site (Fig. 1b; Additional file 1: Tables S2 and S3). Collecting number of differential AS events, the distribution tendency was consistent with forthorder function $\left(R^{2}=1\right)$ and skipped exon mostly occurred in four conditions: SSI, WSI, SSL, and WSL (Fig. 1b, gray lines), with more significant difference of AS events manipulated by skipped exon and mutually exclusive exons (Fig. 1c).

Using Gene Ontology analysis, the molecular functions of genes involving differential AS were enriched, and their numbers were exhibited on Venn diagrams (Fig. $1 \mathrm{~d})$. We recorded the number of overlapped molecular functions in 26 laminated regions (Fig. 1d). It was observed that 1 and 8 intersections were severally presented in SSI and WSI, while 4 and 0 intersections were shown respectively in SSL and WSL (Fig. 1d and e). Hence the probabilities of overlapped molecular functions were $3.85 \%$ (SSI), 30.77\% (WSI), 15.38\% (SSL) and $0.00 \%$ (WSL) between five AS categories (Fig. 1f). These findings suggest that genes affected by different AS categories in ileum exhibit preferential enrichment compared to similar molecular functions as mode I under water-deprivation stress, and various molecular functions as mode II under salt stress; this pattern is opposite to that in liver of stress groups (Fig. 1g).

\section{Changed expression of protein-coding genes in ileum and} liver

Within salt stress, the protein-coding genes with differential expression $(P<0.05)$ consisted of 22 genes (e.g. up-regulated RAI14 and down-regulated MUC6) in ileum and 14 genes (e.g. up-regulated $C D H 11$ and down-regulated LOC105061856) in liver (Fig. 2a-c; Additional file 1: Tables S4 and S5). There were differentially expressed $\quad(P<0.05) \quad 43$ genes $\quad($ e.g. $\quad$ up-regulated $L O C 105076960$ and down-regulated $A Q P 5)$ in ileum and 16 genes (e.g. up-regulated PLIN2 and down-regulated $S D S$ ) in liver under water-deprivation stress (Fig. 2a-c; Additional file 1: Tables S4 and S5). Due to the correlation with sodium ion transport [41], fluid secretion [42] and energy metabolism [43], MUC6, AQP5 and LOC105076960 were screened as resistance genes in ileum. The CDH11, PKP4, TENM1, SDS, LOC105061856, PLIN2 and UPP2 that severally involved in cell-cell adhesion (GO:0098609), cadherin binding (GO:0045296), cell adhesion molecule binding (GO:0050839), gluconeogenesis (GO:0006094), oxygen transport (GO:0015671), long-chain fatty acid transport (GO: 0015909) and uridine phosphorylase activity (GO:0004850) were selected as resistance-related genes in liver by GO enrichment analysis. Based on the results of qRT-PCR experiment, the expression level of MUC6, AQP5, LOC105076960, PKP4, CDH11, TENM1, SDS, LOC105061856, PLIN2 and UPP2 was consistent with RNA-seq data (Fig. 3). Except for salivary secretion with $A Q P 5$, no other pathways associated with salt and water metabolism were detected by KEGG pathway enrichment analysis (Fig. 4a). Notably, expression of MUC6 and AQP5 in ileum and LOC105061856 in liver were down-regulated under both salt stress and water-deprivation stress conditions (Fig. $2 \mathrm{c}$ and Fig. 4 b).

\section{Identification of miRNAs responding to stress}

The miRNA data were obtained in salt and waterdeprivation conditions by RNA-seq (Fig. 2a and b; Additional file 1: Tables S4 and S5). The differentially expressed $(P<0.05) 56$ miRNAs (e.g. up-regulated miR-196b and down-regulated miR-574) under salt stress and 36 miRNAs (e.g. up-regulated miR-362-5p and down-regulated let$7 \mathrm{e})$ under water-deprivation stress were detected in ileum (Fig. 2c). Besides, following the expressive difference $(P<0.05)$, 12 miRNAs (e.g. up-regulated miR-195 and down-regulated miR-199c) under salt stress and 37 miRNAs (e.g. up-regulated miR-543 and down-regulated miR-20a) under waterdeprivation stress were discovered in liver (Fig. 2c). With miRNA target prediction, we were aware that MUC6 mRNA was directed by miR-29b (SSI and WSI) and AQP5 mRNA was aimed by miR-484 (SSI), miR-362-5p (WSI) and miR-96 (WSI). LOC105061856 mRNA was uncovered as objective of miR-195 (SSL), miR-128 (WSL) and miR-148a (WSL), while UPP2 mRNA was an alternative target of miR-128 (WSL). qRT-PCR results showed that the expression trend of miR- 
a

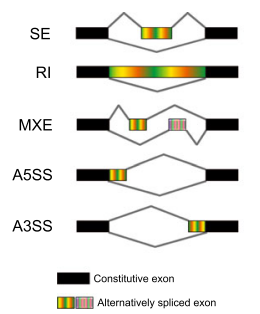

b

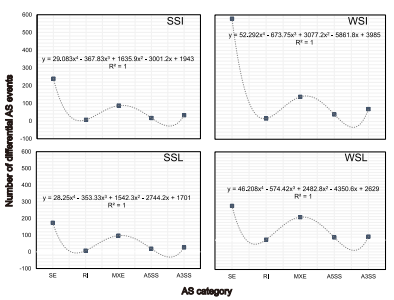

c

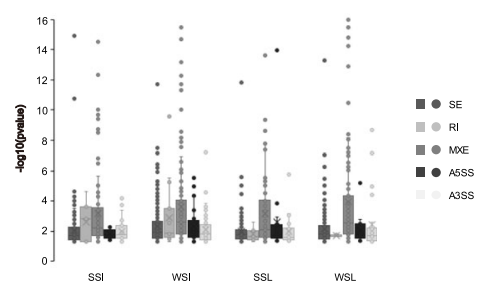

d

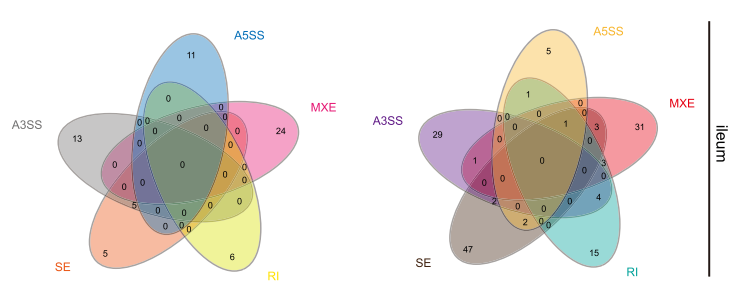

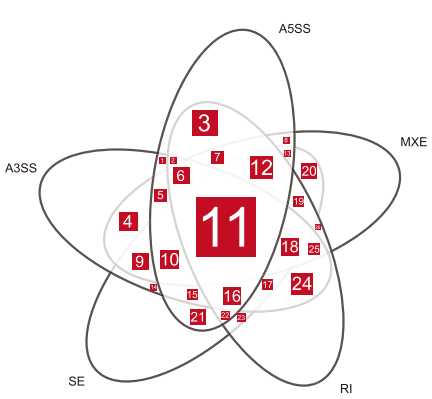

n

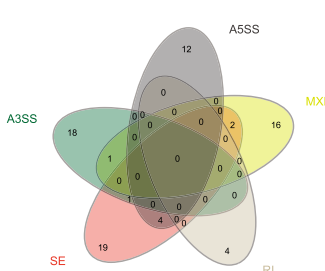

salt stress

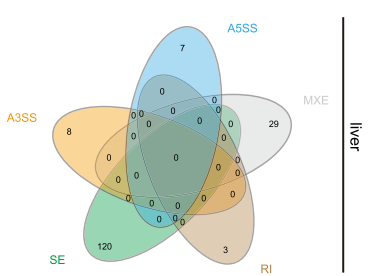

water-deprivation stress

e

g

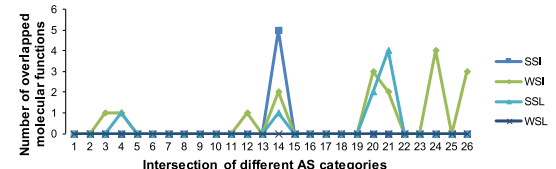

Mode I

AS category 1 AS category 2<smiles>C1CC2CC12</smiles>

Molecular function 1

f

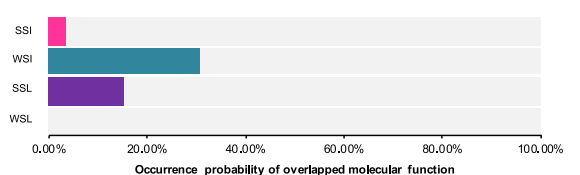

Mode II

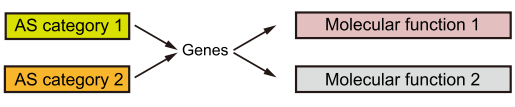

Fig. 1 Alternative splicing events in the ileum and liver of camel under salt stress and water-deprivation stress. a Five categories of alternative splicing. b Number of differential AS events in the five AS categories of SSI, WSI, SSL and WSL. c Distribution of -log 10 ( $p$ value) values of differential AS events in each AS category. $\mathbf{d}$ Number of molecular functions enriched by protein-coding genes involving differential AS events. e Number of overlapped molecular functions on intersections of different AS categories. $\mathbf{f}$ Incidence of enriched similar molecular function from genes regulated by different AS categories. $\mathbf{g}$ Two tendentious modes. AS means alternative splicing. A3SS, A5SS, MXE, RI and SE refer respectively to alternative $3^{\prime}$ splice site, alternative $5^{\prime}$ splice site, mutually exclusive exons, retained intron and skipped exon. SSI, WSI, SSL, and WSL separately indicate ileum under salt stress, ileum under water-deprivation stress, liver under salt stress and liver under water-deprivation stress

29b, miR-484, miR-362-5p, miR-96, miR-195, miR-128 and miR-148a was matched to RNA-seq data (Fig. 3).

\section{LncRNAs and evaluation of RNA-RNA interaction}

For ileum and liver of camel under stresses, the differential lncRNAs $(P<0.05)$ were emerged by RNA-seq (Fig. $2 \mathrm{a}$ and $\mathrm{b}$; Additional file 1: Tables S4-S6). The data of RNA-seq indicated that three up-regulated novel lncRNAs (LNC002765, LNC000855 and LNC001664) were detected under salt stress along with seven upregulated novel lncRNAs (LNC001509, LNC000105, LNC000948, LNC002464, LNC002465, LNC001684 and LNC001664) under water-deprivation stress in ileum (Fig. $2 \mathrm{c}$ and Fig. $4 \mathrm{c}$ ). There were five up-regulated new lncRNAs (LNC001438, LNC003417, LNC003695, LNC000406 and LNC001770) under salt stress and one down-regulated new lncRNA (XM_010950341.1) under water-deprivation stress in liver (Fig. $2 \mathrm{c}$ and Fig. $4 \mathrm{c}$ ). 
a
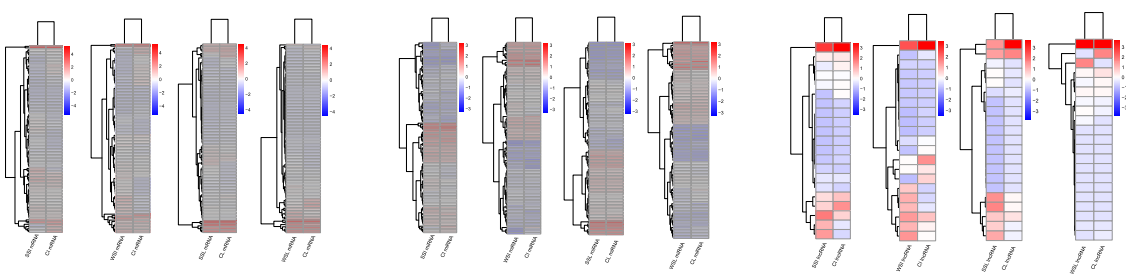

b
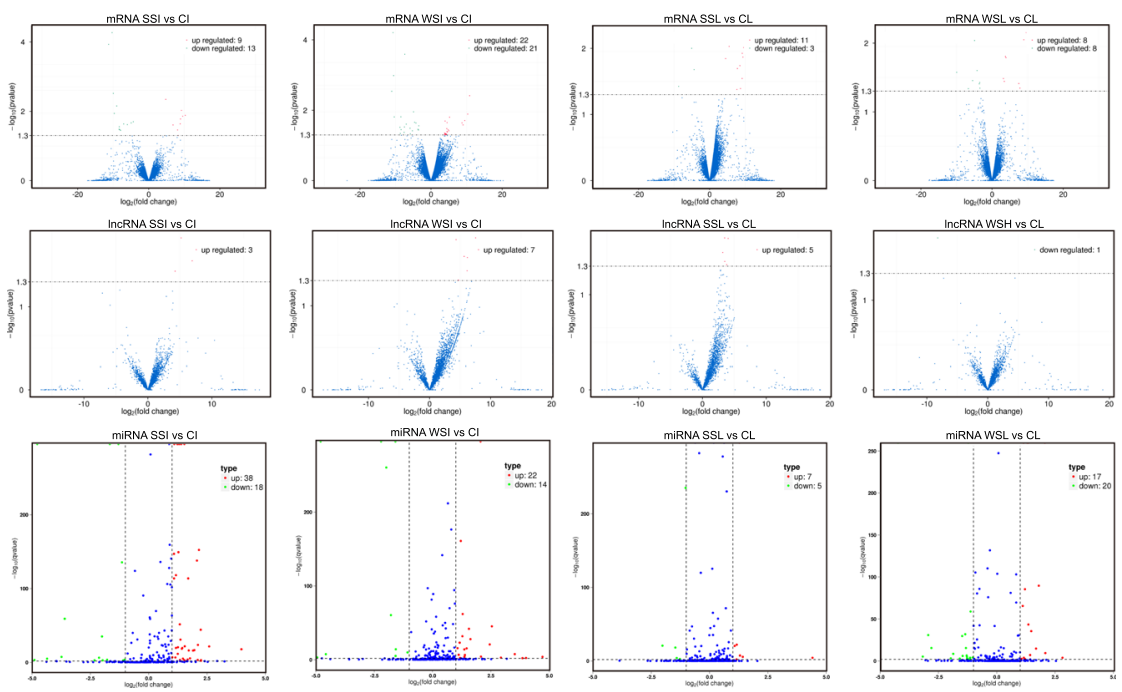

C

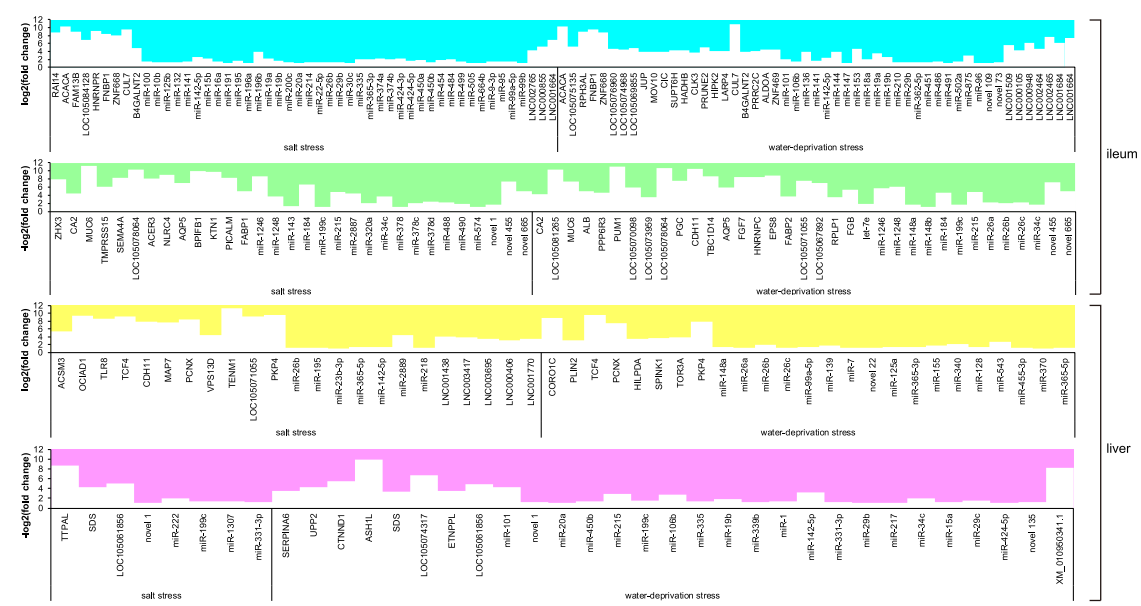

Fig. 2 Differential mRNAs, miRNAs and IncRNAs in ileum and liver under salt stress and water-deprivation stress. a Expressed level of mRNA and IncRNA with value of $\log 10($ FPKM +1$)$, and miRNA with value of $\log 10(T P M+1)$. b Number of differential mRNAs, miRNAs and IncRNAs. $\mathbf{c}$ Log2(fold change) values of up-regulated mRNAs, miRNAs and IncRNAs and -log2(fold change) values of down-regulated mRNAs, miRNAs and IncRNAs. SSI, WSI, CI, SSL, WSL and CL separately indicate ileum under salt stress, ileum under water-deprivation stress, control ileum, liver under salt stress, liver under water-deprivation stress and control liver

Interestingly, we determined that the newfound lncRNA XM_010950341.1 was annotated as one of LOC105065270 transcripts and related to response to water-deprivation stress in camel liver. Apart from coding protein CutA homolog, a type of RNA with unknown function is also transcribed from LOC105065270 in the light of the annotated Camelus bactrianus genome. The transcription of LOC105065270 into RNA sequences may be divided into two directions, comprising messenger RNA of coding protein and long non-coding RNA of performing posttranscriptional regulation. Using ceRNAs (mRNAmiRNA-lncRNA) prediction (Fig. 4d), we found that only LNC001664, let-7e and LOC105076960 mRNA accorded with ceRNA principle in ileum, which LOC105076960 participates in energy buffer and thus may assist in preventing the disorder of ionic gradients by regulating 

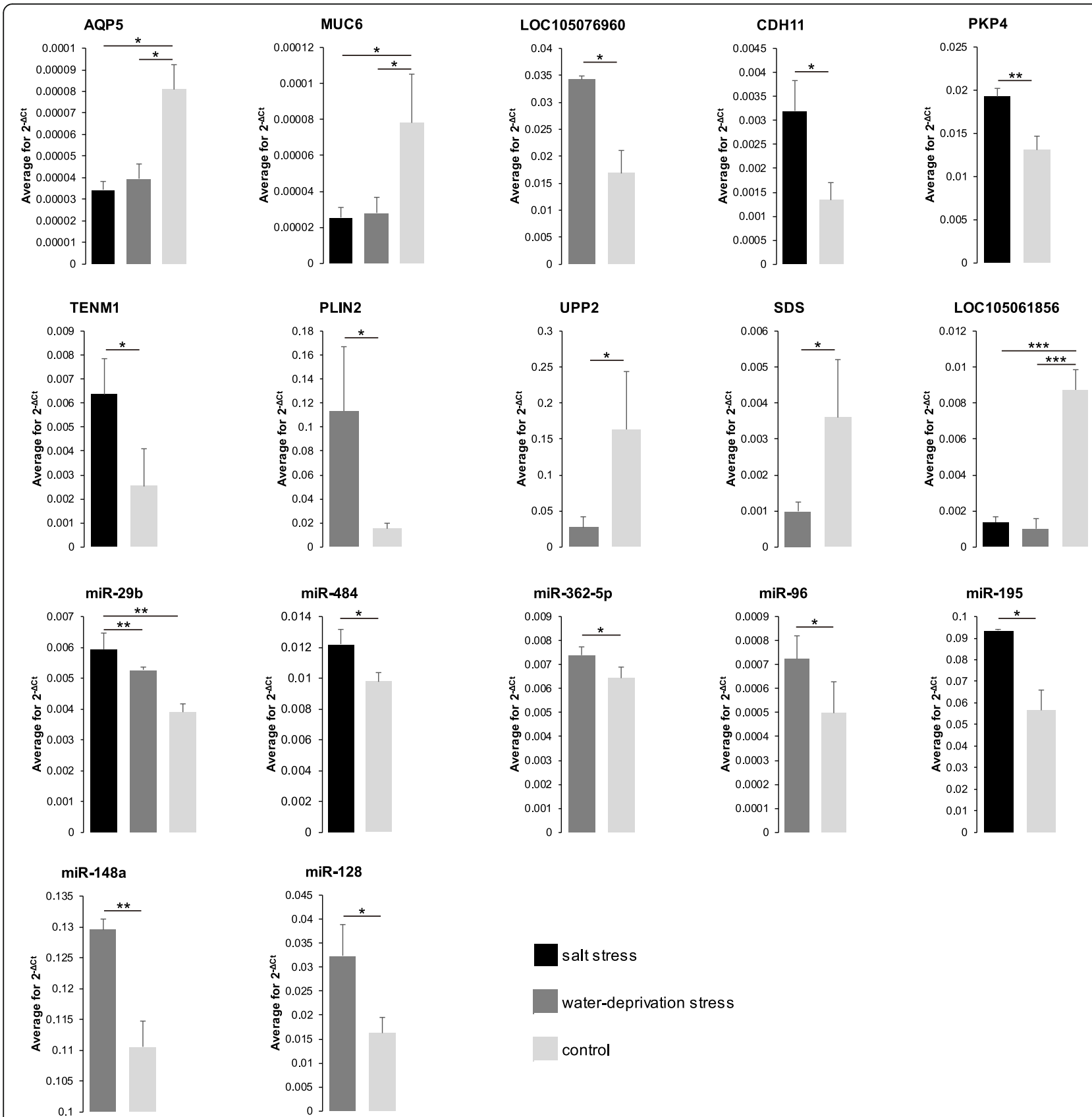

Fig. 3 qRT-PCR detection of candidate water-deprivation resistant genes. Data are presented as mean \pm SD. Symbols: ${ }^{*}, 0.01<P<0.05 ;{ }^{* *}, 0.001<$ $P<0.01$; ${ }^{* *}, P<0.001$

sodium potassium pump [43, 44]. But MUC6 and AQP5 mRNAs that are closely related to salt and water metabolism were not predicted as ceRNA. In liver, LNC001438, LNC003417, LNC001770, miR-199c and TENM1 mRNA were detected to be the important factors for serving ceRNA theory (Fig. 4d).

\section{Discussion}

In order to investigate how camels respond to the salt and water-deprivation stresses, we focused on differential alternative splicing and gene expression in ileum and liver. Based on statistical analysis of differential AS events, we discovered that the skipped exon as a class of AS category is mainly invoked in ileum and liver of camel under salt and water-deprivation stresses. This functional response is supported by a variety of stressrelated studies on biological resistances, such as those to salt, temperature, and air exposure stresses [45]. Intriguingly, two modes were revealed in this test: genes influenced by five AS categories were preferentially 
a

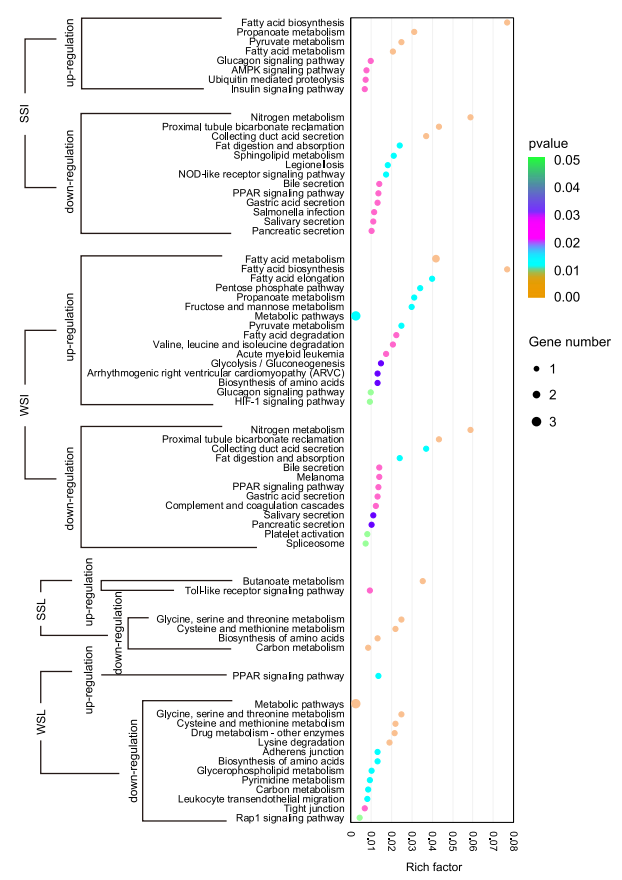

b

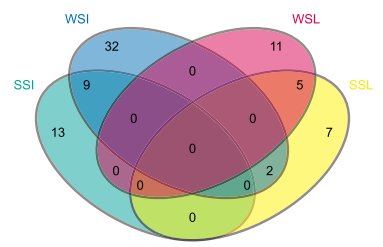

C

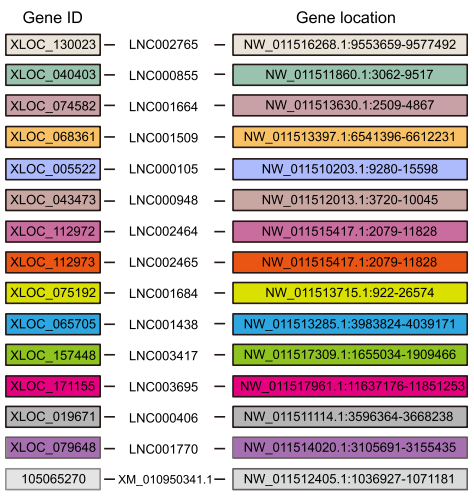

105065270 - XM_010950341.1- NW_011512405.1:1036927-1071181

d
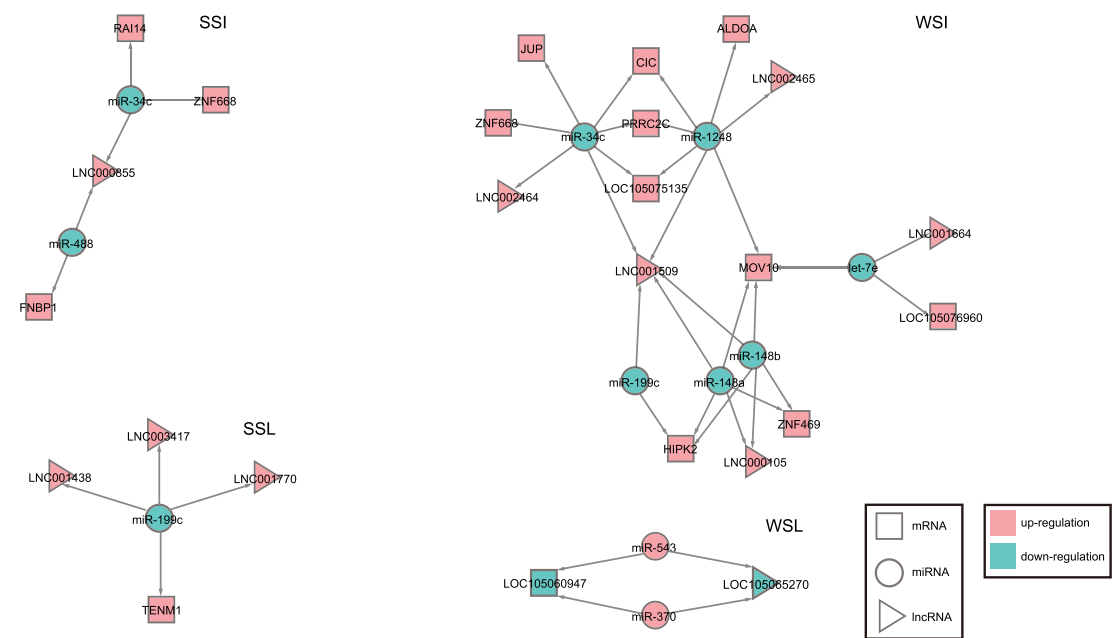

Fig. 4 Bioinformatics analysis for significantly differential $(P<0.05)$ mRNAs, miRNAs and IncRNAs under stress. a KEGG pathway enrichment based on differential protein-coding genes. $\mathbf{b}$ Number of common protein-coding genes between stress groups. $\mathbf{c}$ Detailed genes information of differential IncRNAs. d Potential mRNAs, miRNAs and IncRNAs serving ceRNA theory. SSI, WSI, SSL and WSL separately indicate ileum under salt stress, ileum under water-deprivation stress, liver under salt stress and liver under water-deprivation stress

enriched to similar molecular functions (mode I) under water-deprivation stress and diverse molecular functions (mode II) under salt stress in ileum. By contrast, in liver, the parallel molecular functions enriched by the AS genes as a tendency (mode I) occurred in salt stress group, with varied molecular functions (mode II) in water-deprivation stress group. The results implied that the molecular function enrichment pattern of genes driven by AS was influenced by organ type in response to stress.
Among the protein-coding genes with differential expression, AQP5 encodes aquaporin-5 as a water channel protein located on biological cell membranes that promotes passage of water through the lipid bilayer at high flux $[46,47]$. Scientists confirm that water channel protein enhances the permeability of membranes to water, and enables organism to adapt to salt and drought stresses [48]. AQP5 is supported to participate in water movement in acinar cells $[49,50]$. These biological functions are also involved in sweating and salivary secretion, 
where expression and distribution of AQPs are modified under various xerostomic conditions. Furthermore, AQP5 translocation may improve the water permeability of the apical membranes of sweat glands [51, 52]. In mice, AQP5 deletion in submucosal glands reduced fluid secretion by more than $50 \%$ [42], that is, AQP5 plays an important role in fluid secretion [53]. However, the effects of AQP5 have not been probed thoroughly in camel. There is evidence that AQP2 and AQP3 show stronger expression than in other species, but AQP4 deficiency in camel kidney [5, 54]. MUC6 encoding mucin-6 is a member of the mucin family [55]. Reports reveal that mucin secretion is $\mathrm{Na}^{+} / \mathrm{Ca}^{2+}$ exchanger-dependent such as MUC5AC in goblet cells of the respiratory $[56,57]$, and substantially increases level of intracellular $\mathrm{Na}^{+}$(up to 600-fold) with $\mathrm{Ca}^{2+}$ export [41]. In test outcomes, the gene expression of AQP5 and MUC6 was down-regulated in ileum under salt and water-deprivation stresses. Downregulated $A Q P 5$ appears to maintain osmotic homeostasis and prevent dehydration of cells, and the down-regulated MUC6 probably encourages decreasing mucin secretion and avoiding excessive $\mathrm{Na}^{+}$import by $\mathrm{Na}^{+} / \mathrm{Ca}^{2+}$ exchanger (Fig. 5). In term of camels, weakened import of $\mathrm{Na}^{+}$ into cells is a positive response in high-salt and waterless conditions [58]. In miRNA-mediated interaction in which miRNA suppresses the expression of protein-coding gene, the AQP5 mRNA is predicted as potential target of upregulated miR-484, miR-362-5p and miR-96, while MUC6 mRNA is targeted by up-regulated miR-29b. Another interesting finding was that, under water-deprivation stress, the LOC105076960 mRNA may act as the member of potential ceRNAs containing up-regulated LNC001664, down-regulated let-7e and up-regulated LOC105076960 mRNA in the post-transcriptional regulation level. LOC105076960 encodes mitochondrial creatine kinase (U-type) catalyzing the reversible reaction of "phosphocreatine $+\mathrm{ADP} \rightleftharpoons \mathrm{ATP}+$ creatine" (also called as CK/ PCr system) $[43,59]$. Creatine phosphate (phospho-creatine) serves as a high energy reserve and rapid energy buffer, and works on quick regeneration of ATP in situ, fluctuation of spatial and temporal ATP levels, and energy transfer inside cells [60]. In water-deprivation condition (Fig. 5), the energy reserve may contribute to reducing the amount of sodium ion being pumped outside cells, thus preventing excess glucose into the ileum cells due to sodium ion gradients mediated by sodium-glucose cotransporter (SGLT) [61]. Osmosis unbalance and cell damage induced by massively accumulated glucose are further hindered [62]. Therefore in the present study, miRNAmediated silencing of AQP5 and MUC6 was identified as core positively responding to salt and water-deprivation stresses with ceRNA-related activating of LOC105076960.

In differentially expressed genes of liver under salt stress, TENM1 is reported to play an indispensable role in maintaining integrity of basement membrane, in which the dearth of TENM1 causes local basement membrane deficiency of Caenorhabditis elegans teneurin ortholog [63]. Basement membranes are multifunctional such as constructing filtration barrier, mediating organogenesis and activating tissue repair $[64,65]$, and follow

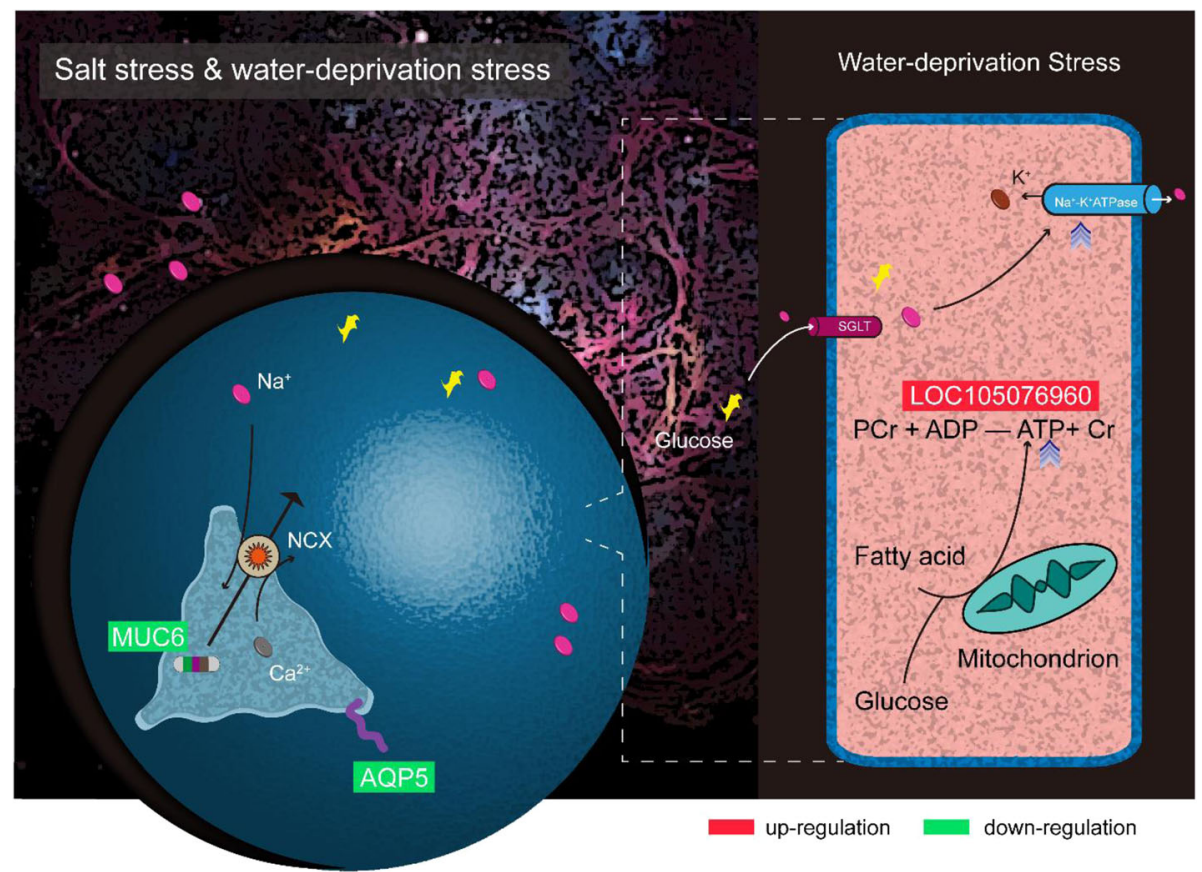

Fig. 5 Weakened sodium ion import and water loss with active energy buffer responding to ambient challenge in camel ileum 
with interest high sodium loading. For instance, sodium hyper-reabsorption pushes glomerular filtration to higher rates [66]; moreover, glomerular hyperfiltration leads to an increase in glomerular basement membrane length [67]. Relying on the basement membrane of its gills, tilapia sustains sodium homeostasis and adapts to seawater by active $\mathrm{Na}^{+} / \mathrm{K}^{+}$-ATPase [68]. In rat colon, sodium invasion switches on remodeling of the basement membrane [69]. The cell-adhesion molecule cadherin-11 is encoded by CDH11 [70-72]. Cadherins compose a family of cell surface proteins that, using the adherens junction as a basis, participate in cell-cell adhesion, an essential process in tissue morphogenesis and integrity [73]. A previous study reported that adherens junctions form defensive barriers and maintain ion homeostasis, and that their functional deficiency triggers ion imbalance and tissue inflammation [74]. In intestinal epithelium, the selective barrier formed by adherens junction supervises absorption of fluid and solutes [75]. The past studies have proved that the overexpressed plakophilin-4 encoded by PKP4 is positioned along cell borders and strengthens cell-cell adhesion via recruiting cadherins to the membrane [76]. LOC105061856 encodes hemoglobin subunit beta which is a component of hemoglobin that partakes in oxygen transport and mitochondrial oxidative phosphorylation [77-79]. There is a reasonable interpretation about how camels succeed in salt resistance by liver (Fig. 6). Specifically, with up-regulated LNC001438, LNC003417 and LNC001770 and downregulated miR-199c, the up-regulated TENM1 involving in ceRNA is conducive to liver survival by protective barrier role of basement membrane, while the up- regulated $C D H 11$ and $P K P 4$ would promote cell-cell adhesion and further attain sodium ion homeostasis by barrier. The down-regulated LOC105061856, mRNA of which was targeted by up-regulated miR-195, is able to slow down aerobic respiration and metabolism through reducing oxygen transported to mitochondria. Several lines of evidence from animal species have demonstrated that responses to high temperatures and arid conditions depend on dormancy, characteristics of which are inactivity and a lowered metabolic rate [80, 81].

Concerning the hepatic genes resisting waterdeprivation stress, the role of $S D S$ is presented as stimulatory gluconeogenesis in hepatocytes [82]. SDS can accelerate the reaction of serine to pyruvate, further increase generation of oxaloacetic acid and glucose in the process of gluconeogenesis [83]. Uridine, a pyrimidine nucleoside, shows restorative effects in positive response to stress in tissues, while mice experiment points out that long-period feeding of uridine arouses glucose intolerance and lipid accumulation in liver [84]. The uridine phosphorylase 2 encoded by UPP2 promotes reaction from uridine to uridine diphosphate glucose and uridine dipho-sphate $\mathrm{N}$-acetylglucosamine which are taken as substrates for glycogen synthesis and the protein of O-linked glycosylation. Gene PLIN2 encodes perilipin-2, also known as adipose differentiation-related protein or adipophilin [85]. In nonadipose tissue, typically in liver, PLIN2 is the most common protein relevant to lipid droplet and its expression usually evokes intracellular lipid accumulation [86]. In addition, PLIN2 is also one of the most abundant proteins in the membrane of milk lipid globule which secretes massive lipid

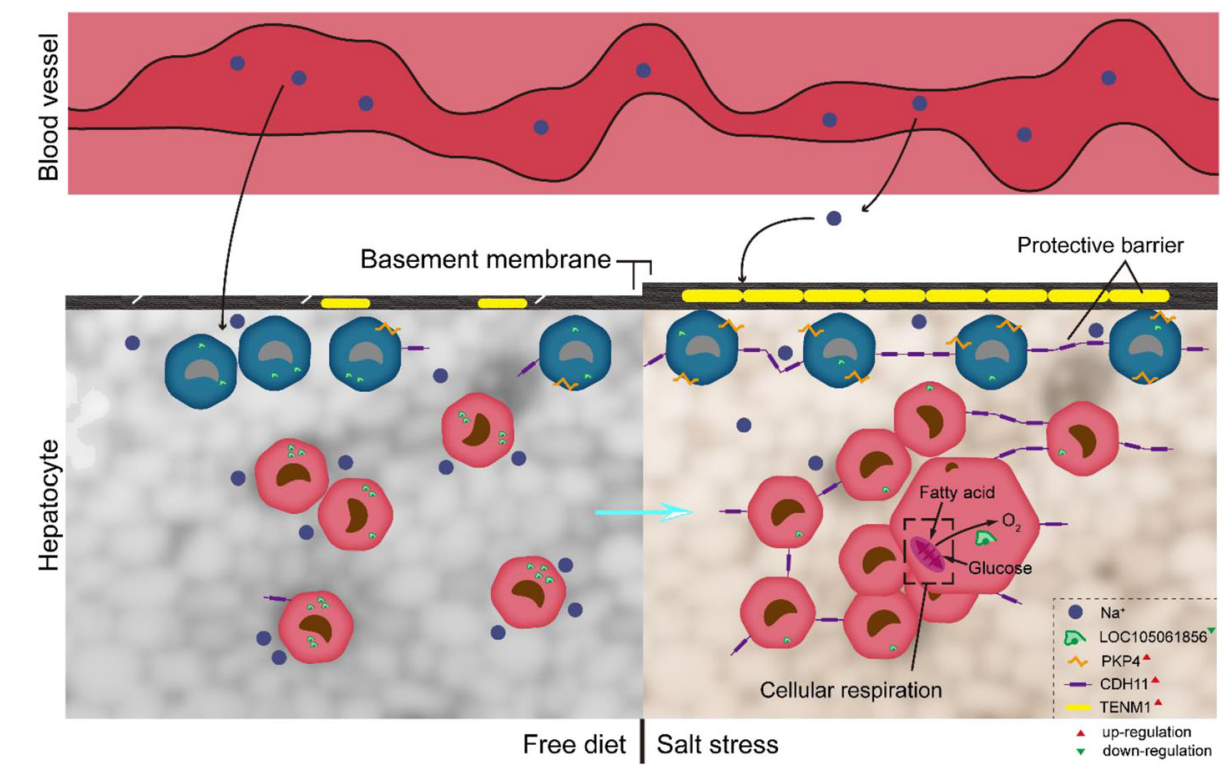

Fig. 6 Advanced protective barrier and sodium ion homeostasis, and reduced aerobic respiration contributing on salt resistance in camel liver 


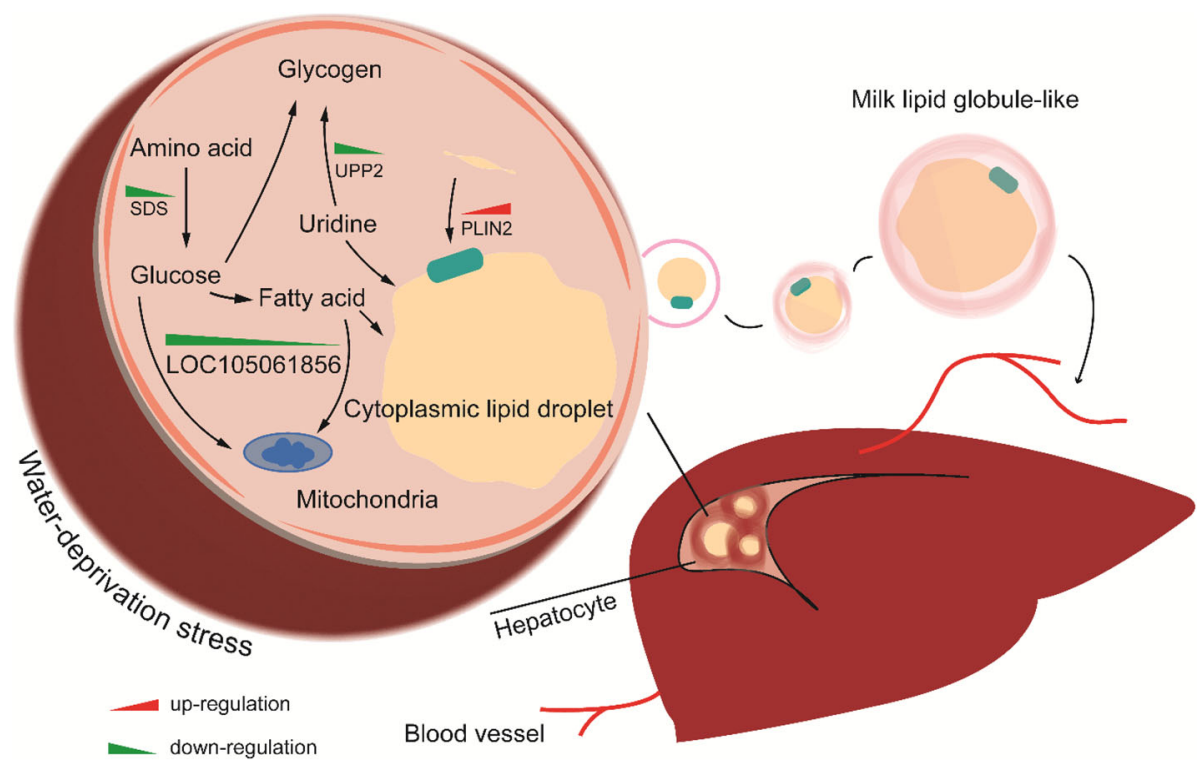

Fig. 7 Improved uridine, glucose and lipid metabolism under water-deprivation stress in camel liver

into milk by a unique process of membrane envelopment of cytoplasmic lipid droplets [87, 88]. The overexpression of PLIN2 increases lipid accumulation and triglyceride concentration in goat mammary epithelial cell [89]. In liver, as for camel responding positively to water-deprivation stress (Fig. 7), the down-regulated UPP2 targeted by up-regulated miR-128 was implied to ensure uridine performing restorative function. In regard to glucose intolerance and lipid deposition induced by uridine accumulation, the down-regulated $S D S$ would help to reduce gluconeogenesis and the up-regulated PLIN2 could boost lipid accumulation and lipid droplet formation, then transfer lipid droplet to blood and deliver it to hump to store fat by membrane envelopment of milk lipid globule-like secretion as the responsible regulation pathway. Similarly, the down-regulated expression of LOC105061856 targeted by up-regulated miR-128 and miR-148a is also considered as a facilitator to decrease the rate of cell aerobic metabolism.

In addition, we note that the present study identified down-regulation of LOC105061856 mRNA in camel liver under salt and water-deprivation stresses, consistent with the absence of its expression in camel renal medulla with water-deprivation condition [90]. This may signify that different organs utilize an overlapped mediation on gene expression to respond to ambient challenges in camels.

\section{Conclusions}

Association analysis was applied on the mRNA, miRNA, and IncRNA data derived by RNA-seq. We unveiled two modes in the enrichment process from AS genes to their molecular functions, responding to stress in ileum and liver. Combined with the results of qRT-PCR, we screened out resistant coding/non-coding genes. In the post-transcriptional regulation level, the targeting relations were identified between resistant mRNAs, miRNAs and lncRNAs trying to explain how camels cope with salt and water-deprivation stresses in ileum and liver. We are hoping to make up for the deficiency in resistance-related research of camel and provide new theoretical inspirations for human diseases induced by high-salt diet. Nevertheless, there still remains a challenging task in amplifying full length of lncRNA genes coupled to water-deprivation condition, so we will seek appropriate approaches to solve it in the future.

\section{Supplementary information}

Supplementary information accompanies this paper at https://doi.org/10. 1186/s40851-020-00159-3.

Additional file $\mathbf{1}$ Table S1. Primer sequences of resistance-related candidate genes. Table S2. Differential alternative splicing events in ileum under salt stress and water-deprivation stress. Table S3. Differential alternative splicing events in liver under salt stress and water-deprivation stress. Table S4. Differential mRNAs, miRNAs and IncRNAs in ileum under salt stress and water-deprivation stress. Table S5. Differential mRNAs, miRNAs and IncRNAs in liver under salt stress and water-deprivation stress. Table S6. Sequence of differential novel IncRNAs in ileum and liver of camel under salt stress and water-deprivation stress.

\section{Abbreviations}

A3SS: Alternative 3' splice site; A5SS: Alternative 5' splice site; AS: Alternative splicing; ceRNAs: Competing endogenous RNAs; GO: Gene Ontology; KEGG: Kyoto Encyclopedia of Genes and Genomes; IncRNA: Long non-coding RNA; miRNA: Micro RNA; MXE: Mutually exclusive exons; ncRNAs: Non-coding RNAs; RI: Retained intron; SE: Skipped exon; SGLT: Sodium-glucose cotransporter; SS: Salt stress; SSI: Ileum under salt stress; SSL: Liver under salt stress; WS: Water-deprivation stress; WSI: Ileum under water-deprivation stress; WSL: Liver under water-deprivation stress 


\section{Acknowledgements}

We thank Zhicheng Dong, Xiao Liu and Yu Ling for camel's feeding and experimental treatment. We are grateful for sampling assistance of Fanhua Meng, Yiyi Liu, Lu Li and Tao Li.

\section{Authors' contributions}

DZ conceived the study and designed the experiments. DZ, JP and YC participated in sampling and performed the experiments. $Y C$ analysed the data and wrote the manuscript. $\mathrm{HZ}$ provided valuable insights in the discussion and revision of the manuscript. The authors read and approved the final manuscript.

\section{Funding}

This work was funded by the National Natural Science Foundation of China (31560313 and 31260271).

\section{Availability of data and materials}

The datasets presented during the current study are available from the corresponding author on reasonable request.

\section{Ethics approval and consent to participate}

Procedures involving animals, their care and humane kill were conducted in conformity with Guidelines on the Humane Treatment of Laboratory Animals (HTLA Pub. Chapter 2-6, revised 2006 in China) and was approved by Animal Care and Use Committee of the Inner Mongolia Agricultural University (IMAU-IACUC-2019-31560313). The written informed consent of experimental research achieved by Shenyuan Wang (animal owner) was obtained.

\section{Consent for publication}

Not applicable.

\section{Competing interests}

The authors declare that they have no competing interests.

\section{Author details}

'College of Life Sciences, Inner Mongolia Agricultural University, No. 306 Zhaowuda Road, Hohhot 010018, P.R. China. Institute of Traditional Chinese Medicine, Tianjin University of Traditional Chinese Medicine, No. 10 Poyanghu Road, Tianjin 301617, P.R. China.

Received: 20 January 2020 Accepted: 21 May 2020

Published online: 05 June 2020

\section{References}

1. Schmidt-Nielsen K. The physiology of the camel. Sci Am. 1959;201:140-51.

2. Rehan S, Qureshi AS. Microscopic evaluation of the heart, kidneys and adrenal glands of one-humped camel calves (Camelus dromedarius) using semi automated image analysis system. J Camel Pract Res. 2006:13:123-7.

3. Benlamlih S, Dahlborn K, Filali RZ, Hossaini-Hilali J. Fluid retention after oral loading with water or saline in camels. Am J Physiol. 1992;262:R915-20.

4. Ben Goumi M, Riad F, Giry J, de la Farge F, Safwate A, Davicco MJ, et al. Hormonal control of water and sodium in plasma and urine of camels during dehydration and rehydration. Gen Comp Endocrinol. 1993;89:378-86.

5. Wu H, Guang X, Al-Fageeh MB, Cao J, Pan S, Zhou H, et al. Camelid genomes reveal evolution and adaptation to desert environments. Nat Commun. 2014;5:5188

6. McHardy GJR, Parsons DS. The absorption of water and salt from the small intestine of the rat. Q J Exp Physiol Cogn Med Sci. 1957;42:33-48.

7. Sandberg AS, Hasselblad C, Hasselblad K, Hultén L. The effect of wheat bran on the absorption of minerals in the small intestine. Br J Nutr. 1982;48:185-91.

8. Mace OJ, Affleck J, Patel N, Kellett GL. Sweet taste receptors in rat small intestine stimulate glucose absorption through apical GLUT2. J Physiol. 2007;582:379-92

9. Moore KL, Dalley AF, Agur AM. Clinically oriented anatomy. 7th ed. Baltimore: Lippincott Williams \& Wilkins; 2013.

10. Curran PF, Solomon AK. Ion and water fluxes in the ileum of rats. J Gen Physiol. 1957:41:143-68.

11. Curran PF. Na, Cl, and water transport by rat ileum in vitro. J Gen Physiol. 1960;43:1137-48

12. Geerling JC, Loewy AD. Central regulation of sodium appetite. Exp Physiol. 2008;93:177-209
13. Kullak-Ublick GA, Stieger B, Meier PJ. Enterohepatic bile salt transporters in normal physiology and liver disease. Gastroenterology. 2004;126:322-42.

14. Burger J, Gochfeld M. Comparisons of nine heavy metals in salt gland and liver of greater scaup (Aythya marila), black duck (Anas rubripes) and mallard (a. platyrhynchos). Comp Biochem Physiol C. 1985;81:287-92.

15. Eddy SR. Non-coding RNA genes and the modern RNA world. Nat Rev Genet. 2001;2:919-29.

16. Bartel DP. MicroRNAs: genomics, biogenesis, mechanism, and function. Cell. 2004;116:281-97.

17. Tonouchi E, Gen Y, Muramatsu T, Hiramoto H, Tanimoto K, Inoue J, et al. miR-3140 suppresses tumor cell growth by targeting BRD4 via its coding sequence and downregulates the BRD4-NUT fusion oncoprotein. Sci Rep. 2018:8:4482.

18. Salmena L, Poliseno L, Tay $Y$, Kats L, Pandolfi PP. A ceRNA hypothesis: the Rosetta stone of a hidden RNA language? Cell. 2011:146:353-8.

19. Leitch I. The feeding of camels. In: Imperial bureau of animal nutrition technical communication no. 13; 1940.

20. Assad F, El-Sherif MMA, Kats L, Pandolfi PP. Effect of drinking saline water and feed shortage on adaptive responses of sheep and camels. Small Ruminant Res. 2002;45:279-90.

21. Custer R, Kramer L, Kennedy S, Bush M. Hematologic effects of xylazine when used for restraint of Bactrian camels. J Am Vet Med Assoc. 1977;171:899-901.

22. Konczal M, Koteja P, Stuglik MT, Radwan J, Babik W. Accuracy of allele frequency estimation using pooled RNA-Seq. Mol Ecol Resour. 2014;14:381-92.

23. Kim D, Pertea G, Trapnell C, Pimentel H, Kelley R, Salzberg SL. TopHat2: accurate alignment of transcriptomes in the presence of insertions, deletions and gene fusions. Genome Biol. 2013;14:R36.

24. Trapnell C, Williams BA, Pertea G, Mortazavi A, Kwan G, Van Baren MJ, et al. Transcript assembly and quantification by RNA-Seq reveals unannotated transcripts and isoform switching during cell differentiation. Nat Biotechnol. 2010;28:511-5.

25. Sun $L$, Luo H, Bu D, Zhao G, Yu K, Zhang C, et al. Utilizing sequence intrinsic composition to classify protein-coding and long non-coding transcripts. Nucleic Acids Res. 2013;41:e166.

26. Kong L, Zhang Y, Ye ZQ, Liu XQ, Zhao SQ, Wei L, et al. CPC: assess the protein-coding potential of transcripts using sequence features and support vector machine. Nucleic Acids Res. 2007;35:W345-9.

27. Bateman A, Birney E, Cerruti L, Durbin R, Etwiller L, Eddy SR, et al. The Pfam protein families database. Nucleic Acids Res. 2002;30:276-80.

28. Punta M, Coggill PC, Eberhardt RY, Mistry J, Tate J, Boursnell C, et al. The Pfam protein families database. Nucleic Acids Res. 2012;40:D290-301.

29. Lin MF, Jungreis I, Kellis M. PhyloCSF: a comparative genomics method to distinguish protein coding and non-coding regions. Bioinformatics. 2011;27:i275-82.

30. Ma L, Bajic VB, Zhang Z. On the classification of long non-coding RNAs. RNA Biol. 2013:10:924-33.

31. Chen EY, Tan CM, Kou Y, Duan Q, Wang Z, Meirelles GV, et al. Enrichr: interactive and collaborative HTML5 gene list enrichment analysis tool. BMC Bioinformatics. 2013;14:128.

32. Kuleshov MV, Jones MR, Rouillard AD, Fernandez NF, Duan Q, Wang Z, et al. Enrichr: a comprehensive gene set enrichment analysis web server 2016 update. Nucleic Acids Res. 2016;44:W90-7.

33. Huang DW, Sherman BT, Lempicki RA. Bioinformatics enrichment tools: paths toward the comprehensive functional analysis of large gene lists. Nucleic Acids Res. 2009;37:1-13.

34. Huang DW, Sherman BT, Lempicki RA. Systematic and integrative analysis of large gene lists using DAVID bioinformatics resources. Nat Protoc. 2009;4:44-57.

35. Mao X, Cai T, Olyarchuk JG, Wei L. Automated genome annotation and pathway identification using the KEGG Orthology (KO) as a controlled vocabulary. Bioinformatics. 2005;21:3787-93.

36. Langmead B, Trapnell C, Pop M, Salzberg SL. Ultrafast and memory-efficient alignment of short DNA sequences to the human genome. Genome Biol. 2009:10:R25.

37. Wen $M$, Shen $Y$, Shi $S$, Tang T. miREvo: an integrative microRNA evolutionary analysis platform for next-generation sequencing experiments. BMC Bioinformatics. 2012;13:140.

38. Friedländer MR, Mackowiak SD, Li N, Chen W, Rajewsky N. miRDeep2 accurately identifies known and hundreds of novel microRNA genes in seven animal clades. Nucleic Acids Res. 2012:40:37-52.

39. Zhou L, Chen J, Li Z, Li X, Hu X, Huang Y, et al. Integrated profiling of microRNAs and mRNAs: microRNAs located on Xq27.3 associate with clear cell renal cell carcinoma. PLoS One. 2010;5:e15224. 
40. Wang L, Feng Z, Wang X, Wang X, Zhang X. DEGseq: an R package for identifying differentially expressed genes from RNA-seq data. Bioinformatics. 2010;26:136-8

41. Wilkins RG, Wilkins PC. The role of calcium and comparable cations in animal behaviour. Cambridge: Royal Society of Chemistry Press; 2003.

42. Verkman AS. Role of aquaporins in lung liquid physiology. Respir Physiol Neurobiol. 2007;159:324-30.

43. Wyss M, Smeitink J, Wevers RA, Wallimann T. Mitochondrial creatine kinase: a key enzyme of aerobic energy metabolism. Biochim Biophys Acta. 1992; 1102:119-66.

44. Howarth C, Gleeson P, Attwell D. Updated energy budgets for neural computation in the neocortex and cerebellum. J Cereb Blood Flow Metab. 2012:32:1222-32.

45. Huang B, Zhang L, Tang X, Zhang G, Li L. Genome-wide analysis of alternative splicing provides insights into stress adaptation of the Pacific oyster. Marine Biotechnol. 2016;18:598-609.

46. Lee MD, Bhakta KY, Raina S, Yonescu R, Griffin CA, Copeland NG, et al. The human Aquaporin-5 gene molecular characterization and chromosomal localization. J Biol Chem. 1996:271:8599-604

47. Agre P. Aquaporin water channels. Biosci Rep. 2004;24:127-63.

48. Xu Y, Hu W, Liu J, Zhang J, Jia C, Miao H, et al. A banana aquaporin gene, MaPIP1;1, is involved in tolerance to drought and salt stresses. BMC Plant Biol. 2014;14:59.

49. Ma T, Song Y, Gillespie A, Carlson EJ, Epstein CJ, Verkman AS. Defective secretion of saliva in transgenic mice lacking aquaporin-5 water channels. J Biol Chem. 1999;274:20071-4.

50. Murdiastuti K, Miki O, Yao C, Parvin MN, Kosugi-Tanaka C, Akamatsu T, et al. Divergent expression and localization of aquaporin 5 , an exocrine-type water channel, in the submandibular gland of Sprague-Dawley rats. Pflugers Arch. 2002:445:405-12.

51. Delporte C, Steinfeld S. Distribution and roles of aquaporins in salivary glands. Biochim Biophys Acta. 1758;2006:1061-70.

52. Inoue R. New findings on the mechanism of perspiration including aquaporin-5 water channel. Curr Probl Dermatol. 2016:51:11-21.

53. Ishikawa Y, Cho G, Yuan Z, Inoue N, Nakae Y. Aquaporin-5 water channel in lipid rafts of rat parotid glands. Biochim Biophys Acta. 1758;2006:1053-60.

54. Wang J, Li H, Huang Z, Shao B, Wang J. Renal expression and functions of AQP1 and AQP2 in bactrian camel (Camelus bactrianus). J Camel Pract Res. 2014;21:153-60.

55. Bartman AE, Buisine MP, Aubert JP, Niehans GA, Toribara NW, Kim YS, et al. The MUC6 secretory mucin gene is expressed in a wide variety of epithelial tissues. J Pathol. 1998;186:398-405.

56. Rogers DF. Physiology of airway mucus secretion and pathophysiology of hypersecretion. Respir Care. 2007;52:1134-46.

57. Mitrovic S, Nogueira C, Cantero-Recasens G, Kiefer K, Fernández-Fernández $J M$, Popoff JF, et al. TRPM5-mediated calcium uptake regulates mucin secretion from human colon. Elife. 2013;2:e00658.

58. Cao Y, Zhang D, Zhou H. Key genes differential expressions and pathway involved in salt and water-deprivation stresses for renal cortex in camel. BMC Mol Biol. 2019;20:11.

59. Wyss M, Kaddurah-Daouk R. Creatine and creatinine metabolism. Physiol Rev. 2000;80:1107-213.

60. Wallimann T, Wyss M, Brdiczka D, Nicolay K, Eppenberger HM. Intracellular compartmentation, structure and function of creatine kinase isoenzymes in tissues with high and fluctuating energy demands: the 'phosphocreatine circuit' for cellular energy homeostasis. Biochem J. 1992;281:21-40.

61. Lambotte S, Veyhl M, Köhler M, Morrison-Shetlar Al, Kinne RK, Schmid M, et al. The human gene of a protein that modifies $\mathrm{Na(+)-D-glucose} \mathrm{CO}-$ transport. DNA Cell Biol. 1996;15:769-77.

62. Donnini $D$, Zambito AM, Perrella G, Ambesi-Impiombato FS, Curcio F. Glucose may induce cell death through a free radical-mediated mechanism. Biochem Biophys Res Commun. 1996;219:412-7.

63. Trzebiatowska A, Topf U, Sauder U, Drabikowski K, Chiquet-Ehrismann R. Caenorhabditis elegans teneurin, ten-1, is required for gonadal and pharyngeal basement membrane integrity and acts redundantly with integrin ina-1 and dystroglycan dgn-1. Mol Biol Cell. 2008;19:3898-908.

64. Hill RW. Animal physiology. Sunderland: Sinauer Associates Press; 2016.

65. Mak KM, Mei R. Basement membrane type IV collagen and laminin: an overview of their biology and value as fibrosis biomarkers of liver disease. Anat Rec. 2017;300:1371-90.
66. Vallon V, Thomson SC. The tubular hypothesis of nephron filtration and diabetic kidney disease. Nat Rev Nephrol. 2020;16:317-36.

67. Chagnac A, Zingerman B, Rozen-Zvi B, Herman-Edelstein M. Consequences of glomerular hyperfiltration: the role of physical forces in the pathogenesis of chronic kidney disease in diabetes and obesity. Nephron. 2019:143:38-42.

68. Verbost PM, Schoenmakers TJ, Flik G, Wendelaar Bonga SE. Kinetics of ATPand $\mathrm{Na}(+)$-gradient driven $\mathrm{Ca} 2+$ transport in basolateral membranes from gills of freshwater- and seawater-adapted tilapia. J Exp Biol. 1994;186:95-108

69. Lindholm M, Manon-Jensen T, Madsen GI, Krag A, Karsdal MA, Kjeldsen J, et al. Extracellular matrix fragments of the basement membrane and the interstitial matrix are serological markers of intestinal tissue remodeling and disease activity in dextran sulfate sodium colitis. Dig Dis Sci. 2019:64:3134-42.

70. Okazaki M, Takeshita S, Kawai S, Kikuno R, Tsujimura A, Kudo A, et al. Molecular cloning and characterization of OB-cadherin, a new member of cadherin family expressed in osteoblasts. J Biol Chem. 1994;269:12092-8.

71. Gumbiner BM. Cell adhesion: the molecular basis of tissue architecture and morphogenesis. Cell. 1996;84:345-57.

72. Kremmidiotis G, Baker E, Crawford J, Eyre HJ, Nahmias J, Callen DF. Localization of human cadherin genes to chromosome regions exhibiting cancer-related loss of heterozygosity. Genomics. 1998:49:467-71.

73. Sannigrahi MK, Srinivas S, Rakshit S. The prospects of cadherin-23 as a mediator of homophilic cell-cell adhesion. Adv Exp Med Biol. 2018;1112:99105.

74. Gonschior H, Haucke V, Lehmann M. Super-resolution imaging of tight and adherens junctions: challenges and open questions. Int J Mol Sci. 2020;21: 744.

75. Garcia-Hernandez V, Quiros M, Nusrat A. Intestinal epithelial claudins: expression and regulation in homeostasis and inflammation. Ann N Y Acad Sci. 2017;1397:66-79.

76. Keil R, Schulz J, Hatzfeld M. p0071/PKP4, a multifunctional protein coordinating cell adhesion with cytoskeletal organization. Biol Chem. 2013; 394:1005-17.

77. Maton A, Hopkins J, Johnson S, MCLaughlin DLCW, Warner MQ, Wright JD. Wright human biology and health. Upper Saddle River: Prentice Hall Press; 1993.

78. Sidell BD, O'Brien KM. When bad things happen to good fish: the loss of hemoglobin and myoglobin expression in Antarctic icefishes. J Exp Biol. 2006;209:1791-802.

79. Biagioli M, Pinto M, Cesselli D, Zaninello M, Lazarevic D, Roncaglia P, et al. Unexpected expression of alpha- and beta-globin in mesencephalic dopaminergic neurons and glial cells. Proc Natl Acad Sci U S A. 2009;106:15454-9.

80. McNab BK. The physiological ecology of vertebrates: a view from energetics. Ithaca: Cornell University Press; 2002.

81. Kozak LP, Young ME. Heat from calcium cycling melts fat. Nat Med. 2012;18: $1458-9$.

82. Sun L, Bartlam M, Liu Y, Pang H, Rao Z. Crystal structure of the pyridoxal-5'phosphate-dependent serine dehydratase from human liver. Protein Sci. 2005;14:791-8.

83. Snell K. Enzymes of serine metabolism in normal, developing and neoplastic rat tissues. Adv Enzyme Regul. 1984;22:325-400.

84. Urasaki Y, Pizzorno G, Le $\Pi$. Chronic uridine administration induces fatty liver and pre-diabetic conditions in mice. PLoS One. 2016;11: e0146994

85. Makino A, Hullin-Matsuda F, Murate M, Abe M, Tomishige N, Fukuda M, et al. Acute accumulation of free cholesterol induces the degradation of perilipin 2 and Rab18-dependent fusion of ER and lipid droplets in cultured human hepatocytes. Mol Biol Cell. 2016;27:3293-304.

86. Greenberg AS, Egan JJ, Wek SA, Garty NB, Blanchette-Mackie EI, Londos C Perilipin, a major hormonally regulated adipocyte-specific phosphoprotein associated with the periphery of lipid storage droplets. J Biol Chem. 1991;266: 11341-6.

87. Heid HW, Schnolzer M, Keenan TW. Adipocyte differentiation-related protein is secreted into milk as a constitute of milk lipid globule membrane. Biochem J. 1996;320:1025-30

88. Chong BM, Reigan P, Mayle-Combs KD, Orlicky DJ, McManaman JL. Determinants of adipophilin function in milk lipid formation and secretion. Trends Endocrinol Metab. 2011:22:211-7.

89. Shi HB, Yu K, Luo J, Li J, Tian HB, Zhu JJ, et al. Adipocyte differentiationrelated protein promotes lipid accumulation in goat mammary epithelial cells. J Dairy Sci. 2015;98:6954-64. 
90. Zhang D, Pan J, Cao J, Cao Y, Zhou H. Screening of drought-resistance related genes and analysis of promising regulatory pathway in camel renal medulla. Genomics. 2020;112:2633-9.

\section{Publisher's Note}

Springer Nature remains neutral with regard to jurisdictional claims in published maps and institutional affiliations.

Ready to submit your research? Choose BMC and benefit from:

- fast, convenient online submission

- thorough peer review by experienced researchers in your field

- rapid publication on acceptance

- support for research data, including large and complex data types

- gold Open Access which fosters wider collaboration and increased citations

- maximum visibility for your research: over $100 \mathrm{M}$ website views per year

At $B M C$, research is always in progress. 